\title{
Stability of Digital Controls of Flexible/Vibratory Aerospace/Automobile Systems by the Graph Norm
}

\begin{abstract}
Marcelo R. A.C. Tredinnick
Santa Ursula University (USU) - Electrical Engineering Department. Rua Fernando Ferrari, 75, prédio VI - sétimo andar. Botafogo - Rio de Janeiro - Brasil - CEP 22231-040. tredi@osite.com.br

Marcelo Lopes de O. e Souza National Institute for Space Research - INPE / Space Mechanics and Control Division - DMC. Av. dos Astronautas, 1758, CEP: 12201-970, Jardim da Granja. São José dos Campos - SP - Brasil.

Copyright (C) 2004 Society of Automotive Engineers, Inc marcelo@dem.inpe.br
\end{abstract}

\begin{abstract}
In this work we study the stability of digital controls of flexible/Vibratory aerospace/automobile systems by the graph norm technique, occurring in sampled-data control systems due to sampling period variations. To do so, this work tries to establish regions (graphs) of stability and instability in a Banach Space, the distances (norms) between them and a given design to detect analytically and/or numerically its margins of stability or conditions of instability. Based on that, we sketch the first steps for a design methodology of stable digital controllers of flexible/vibratory systems embedded in a sampled-data system with adjustable sampling periods of $\mathrm{A} / \mathrm{D}$ and $\mathrm{D} / \mathrm{A}$ converters. A short tutorial about the graph norm technique is also given and some theoretical results as well numerical results are shown. This work was done in two folds to unmask the stability secrets hidden in a general sampled-data control system, until today not revelated. The first part we have used the graph norm and at the second part we made use of the Liapunov stability theory.

\section{PART I: TRIALS THROUGH THE NORM GRAPH TO OBTAIN SOME INFORMATION ABOUT STABILITY REGIONS FOR SAMPLED CONTROL SYSTEMS AS FUNCTION OF THE SAMPLING PERIOD}

As explained in [1], the true discrete could be given by

$$
\mathrm{G}_{\mathrm{T}}(\mathrm{z})=\mathrm{G}_{*, \mathrm{~T}}(\mathrm{z})+\left.\frac{1}{\mathrm{~T}} \sum_{\substack{\mathrm{k} \neq 0 \\ \mathrm{k}=-\infty}}^{\infty} \frac{1-\mathrm{e}^{-\mathrm{sT}}}{\mathrm{s}} \cdot \frac{\mathrm{G}(\mathrm{s})}{\mathrm{s}}\right|_{\mathrm{s}=\mathrm{j}\left(\omega_{\mathrm{a}}-\mathrm{k} \frac{2 \pi}{\mathrm{T}}\right)}
$$

where the first term of the second member is the z-transform of the plant and the second term is the aliasing rewrite below,

$$
\Delta \mathrm{G}_{*}(\mathrm{z})=\mathrm{H}_{\mathrm{T}}(\mathrm{z})=\left.\frac{2}{\mathrm{~T}} \sum_{\mathrm{k} \neq 1}^{\infty} \frac{1-\mathrm{e}^{-\mathrm{sT}}}{\mathrm{s}} \cdot \frac{\mathrm{G}(\mathrm{s})}{\mathrm{s}}\right|_{\mathrm{s}=\mathrm{j}\left(\omega_{\mathrm{a}}-\mathrm{k} \frac{2 \pi}{\mathrm{T}}\right)}
$$

Eq 2

For stability study is convenient to suppose that this aliasing term can converge to a value $\mathrm{M}<\infty$

$$
\mathrm{M}=\sup _{\omega}\left\{\left\|\Delta \mathrm{G}_{*}(\mathrm{z})\right\|_{\infty}\right\}
$$

We can try calculate a general expression to $M$ as follows,

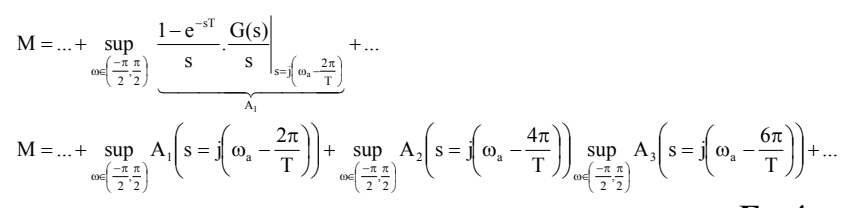

Eq 4

From the equation above be $A_{k}$ a general term given by, 


$$
A_{k}\left(s=j\left(\omega_{a}-\frac{2 k \pi}{T}\right)\right)=\left.\frac{1-e^{-s T}}{s} \cdot \frac{G(s)}{s}\right|_{s=j\left(\omega_{a}-\frac{2 k \pi}{T}\right)}
$$

Eq 5

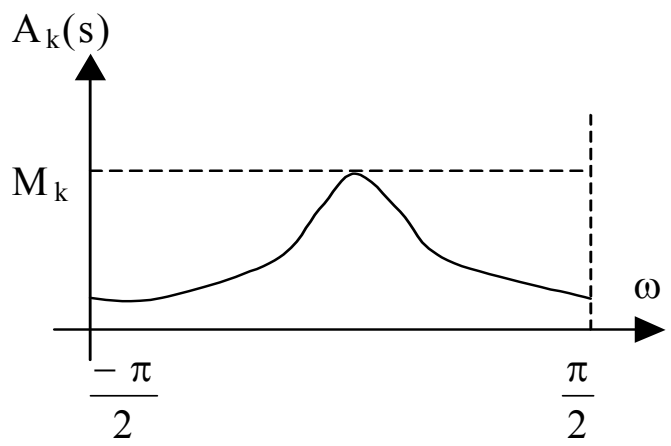

Figure 2: convergence test

Following with some calculations we can attain that,

$$
\begin{aligned}
& \mathrm{M}=\sum_{\mathrm{k} \in \mathrm{N}^{*}} \mathrm{M}_{\mathrm{k}} \\
& \mathrm{M}=\left.\sum_{\mathrm{k} \in \mathrm{N}^{*}}\left\|\mathrm{~A}_{\mathrm{k}}(\mathrm{s})\right\|_{\infty}\right|_{\mathrm{s}=\mathrm{j}\left(\omega_{\mathrm{a}}-\frac{\mathrm{k} 2 \pi}{\mathrm{T}}\right)}
\end{aligned}
$$

Eq 6

Is $\mathrm{M}$ convergent? $\mathrm{M}$ will be limited if the series that define it is convergent. We will verify a case of convergence. By other side is important remember that, by hypothesis, although on has a limited $M$ high disturbances can instabilize the sampled-data system.

We will use the transfer function as a rational form $\mathrm{G}(\mathrm{s})=\frac{\mathrm{n}(\mathrm{s})}{\mathrm{d}(\mathrm{s})}$

Applying this rational form in $\mathrm{M}$,

$M=\sum_{k=1}^{\infty} \sup _{\omega \in\left(\frac{-\pi}{2}, \frac{\pi}{2}\right)} \frac{1-e^{-j \omega T} \cdot e^{-j 2 k \pi}}{-\left(\omega+\frac{2 k \pi}{T}\right)^{2}} \cdot \frac{n\left(j \omega+j \frac{2 k \pi}{T}\right)}{d\left(j \omega+j \frac{2 k \pi}{T}\right)}$

Eq 7

Remembering that $\left|e^{-\mathrm{j} 2 \mathrm{k} \pi}\right|=1$, finally,

$$
M=\sum_{k=1}^{\infty} \sup _{\omega \in\left(\frac{-\pi}{2}, \frac{\pi}{2}\right)} \frac{1-e^{-j \omega T} \cdot e^{-j 2 k \pi}}{-\left(\omega^{2}+4 \omega k \frac{\pi}{T}+\frac{4 k^{2} \pi^{2}}{T^{2}}\right)} \cdot \frac{n\left(j \omega+j \frac{2 k \pi}{T}\right)}{d\left(j \omega+j \frac{2 k \pi}{T}\right)}
$$

$\operatorname{Eq} 8$

That is a general expression for the upper bound $\mathrm{M}$.

Example: If $\mathrm{n} / \mathrm{d}$ is a rigid body with inertia $\mathrm{J} \mathrm{n} / \mathrm{d}=\frac{1}{\mathrm{Js}^{2}}$, than,

$$
\mathrm{M}=\frac{1}{\mathrm{~J}} \sum_{\mathrm{k}=1}^{\infty} \sup _{\omega \in\left(\frac{-\pi, \pi}{2}, \frac{\pi}{2}\right)} \frac{1-\mathrm{e}^{-\mathrm{j} \omega \mathrm{T}} \cdot \mathrm{e}^{-\mathrm{j} k \mathrm{k} \pi}}{\omega^{4}+8\left(\omega \mathrm{k} \frac{\pi}{\mathrm{T}}+\frac{\mathrm{k}^{2} \pi^{2}}{\mathrm{~T}^{2}}\right)+16\left(\omega^{2} \frac{\mathrm{k}^{2} \pi^{2}}{\mathrm{~T}^{2}}+2 \omega \frac{\mathrm{k}^{3} \pi^{3}}{\mathrm{~T}^{3}}+\frac{\mathrm{k}^{4} \pi^{4}}{\mathrm{~T}^{4}}\right)}
$$

For a $\mathrm{k}$ very greater than the unity the $\mathrm{k}^{\text {th }}$ term of $\mathrm{M}$ can assume the following format,

$$
M_{k}=\frac{T^{4}}{J} \cdot \frac{1-e^{-j \omega T} \cdot e^{-j 2 k \pi}}{16 k^{4} \pi^{4}}
$$

It shows that this $\mathrm{k}^{\text {th }}$ term can be despicable if $\mathrm{T}$ is low but if $\mathrm{T}$ is high this term can diverge. If $\mathrm{M}$ diverge is clear that the sampled-data control system will diverge too. The disturbances over the plant due the aliasing will very high.

Example: Consider now that $G(s)=\frac{1}{s(s+1)}$

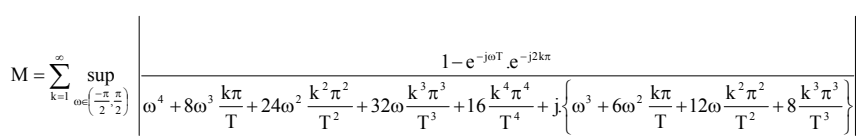

Eq 11

Its $\mathrm{k}^{\text {th }}$ term is,

$$
M_{K}=\frac{T^{4}}{8 k^{3} \pi^{3} \sqrt{4 k^{2} \pi^{2}+T^{2}}}
$$

For many values for $\mathrm{T}$ we can see in the Figure that this series converges.

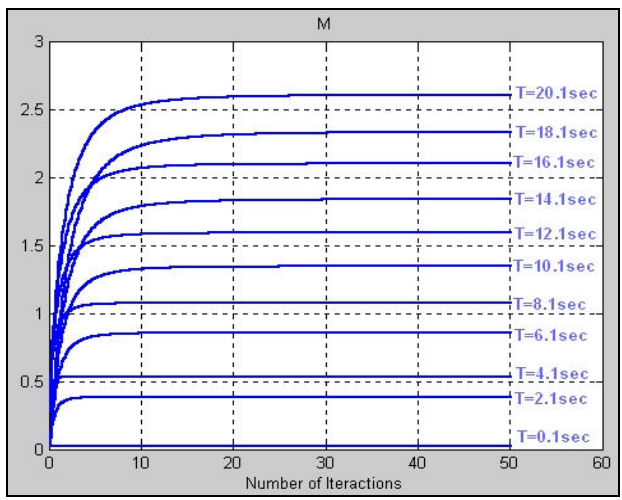

Figura 1: convergence of $M$.

Example: now suppose that $\mathrm{G}(\mathrm{s})=\frac{1}{(\mathrm{~s}+1) \cdot(\mathrm{s}+2)}$

In this case,

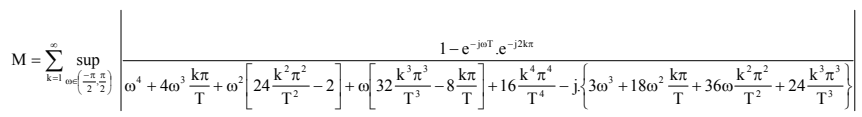

Eq 13

Its $\mathrm{k}^{\text {th }}$ term is,

$M_{K}=\frac{T^{4}}{16 k^{4} \pi^{4}-j 24 T^{2} k^{3} \pi^{3}}$

Eq 14

As shown in the Figure, $\mathrm{M}$ is again convergent. 


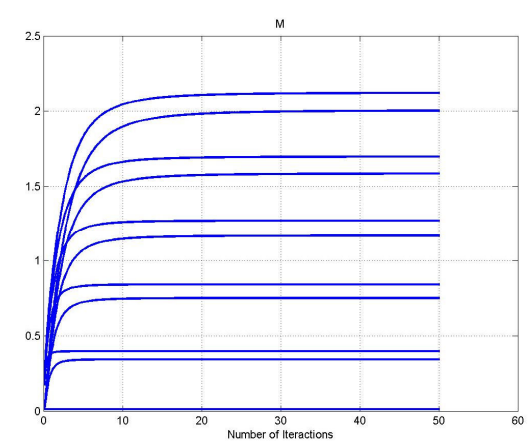

Figura 2: convergence of $\mathrm{M}$.

From these results and the knowledge about graph norm (see Appendix), we can sketch the following Lemma, presented here without proof,

Hypothesis: for a sampled data control system with sampling period $\mathrm{T}$ we can suppose that the closed-loop stability can guaranteed if

$$
\left\|\mathrm{G}_{\mathrm{T}}\right\|_{\text {Grafo }}=\inf \left\{\|\mathrm{d}\|_{\infty},\|\mathrm{n}\|_{\infty}\right\}<\mathrm{M}(\mathrm{T})
$$

\section{PART II: TRIALS THROUGH LIAPUNOV THEORY TO OBTAIN SOME INFORMATION ABOUT STABILITY REGIONS FOR SAMPLED CONTROL SYSTEMS AS FUNCTION OF THE SAMPLING PERIOD}

As given in [3] a class of distributed parameter systems, which includes flexible structures, may be described by,

$$
\dot{\mathrm{v}}=\mathrm{Av}+\mathrm{Bu}
$$

Eq 15

with $\mathrm{v}(0)=\mathrm{v}_{\mathrm{o}}$ and $\mathrm{u}$ is the direct velocity feedback control (DVFB) that gives,

$$
\dot{\mathrm{v}}=\mathrm{A}_{\mathrm{c}} \mathrm{V}
$$

where, $\mathrm{A}_{\mathrm{c}}=\mathrm{A}-\mathrm{BQB}$ ' where $\mathrm{Q}$ is positive-definite.

Using the Backward s-z mapping Balas ${ }^{[3]}$ has presented the following discrete-time expression for the control system,

$$
\mathrm{v}_{\mathrm{k}+1}=\mathrm{v}_{\mathrm{k}}+\mathrm{T} \cdot \mathrm{A}_{\mathrm{c}} \cdot \mathrm{v}_{\mathrm{k}}
$$

And using a Liapunov function given by,

$$
\mathrm{V}\left(\mathrm{v}_{\mathrm{k}}\right)=1 / 2 \mathrm{v}_{\mathrm{k}}^{\prime} \mathrm{Pv}_{\mathrm{k}}
$$

where $\mathrm{P}$ is positive-definite, could be shown that

$$
\Delta \mathrm{V}_{\mathrm{k}}=-\mathrm{T} / 2 \mathrm{v}_{\mathrm{k}}^{\prime}\left[\mathrm{Q}-\mathrm{TA}_{\mathrm{c}}^{\prime} \mathrm{PA}_{\mathrm{c}}\right] \mathrm{V}_{\mathrm{k}}
$$

that we must have $\Delta \mathrm{V}_{\mathrm{k}}<0$ for the asymptotically stability, as shown in the following theorem,

Theorem 1 (Balas ${ }^{[3]}$ ): the discrete-time system $v_{k+1}$ remains stable as long as

$$
\mathrm{T}<\frac{\lambda_{\text {min }}(\mathrm{Q})}{\lambda_{\text {max }}\left(\mathrm{A}_{\mathrm{c}}^{\prime} \mathrm{PA}_{\mathrm{c}}\right)}
$$

If we use the Tustin rule ${ }^{[10,11]}$ as the $s-z$ mapping we can obtain a more accurate and general result that done in [3] as follows,

Theorem 2: the discrete-time system $\mathrm{v}_{\mathrm{k}+1}$ remains stable as long as

$$
\lambda_{\text {min }}(\mathrm{Q})>\lambda_{\text {max }}\left(\left(\mathrm{e}^{\mathrm{A}_{\mathrm{c}} \mathrm{T}}\right)^{\prime} \mathrm{Pe}^{\mathrm{A}_{\mathrm{c}} \mathrm{T}}\right)
$$

Proof: the equation $\dot{\mathrm{V}}=\mathrm{A}_{\mathrm{c}} \mathrm{V}$ mapped by Tustin rule is given by

$$
\begin{aligned}
& 2 / \mathrm{T}\left(\mathrm{v}_{\mathrm{k}+1}-\mathrm{v}_{\mathrm{k}}\right)=\mathrm{A}_{\mathrm{c}}\left(\mathrm{v}_{\mathrm{k}+1}+\mathrm{v}_{\mathrm{k}}\right) \\
& \mathrm{v}_{\mathrm{k}+1}=\left[2 \mathrm{I}-\mathrm{TA} \mathrm{A}_{\mathrm{c}}\right]^{-1}\left[2 \mathrm{I}+\mathrm{TA} A_{\mathrm{c}}\right] \mathrm{v}_{\mathrm{k}}
\end{aligned}
$$

Now making use that the Padé approximant for the exponential function is gven by,

$$
\begin{aligned}
& \mathrm{e}^{\mathrm{A}_{\mathrm{c}} \mathrm{T}}=\left[\mathrm{e}^{-\frac{\mathrm{T}}{2} \mathrm{~A}_{\mathrm{c}}}\right]^{-1}\left[\mathrm{e}^{\frac{\mathrm{T}}{2} \mathrm{~A}_{\mathrm{c}}}\right]=\left[\mathrm{I}-\mathrm{A}_{\mathrm{c}} \frac{\mathrm{T}}{2}+\ldots\right]^{-1}\left[\mathrm{I}+\mathrm{A}_{\mathrm{c}} \frac{\mathrm{T}}{2}+\ldots\right] \\
& \mathrm{e}^{\mathrm{A}_{\mathrm{c}} \mathrm{T}} \approx\left[\mathrm{I}-\mathrm{A}_{\mathrm{c}} \frac{\mathrm{T}}{2}\right]^{-1}\left[\mathrm{I}+\mathrm{A}_{\mathrm{c}} \frac{\mathrm{T}}{2}\right]
\end{aligned}
$$

As we see it is possible reconstruct the rational form presented by the exact exponential form,

$$
\mathrm{v}_{\mathrm{k}+1}=\mathrm{e}^{\mathrm{A}_{\mathrm{c}} \mathrm{T}} \mathrm{v}_{\mathrm{k}}
$$

$\mathrm{Be} \mathrm{P}>0$ and the Liapunov functions,

$$
\begin{aligned}
& \mathrm{V}\left(\mathrm{v}_{\mathrm{k}}\right)=1 / 2 \mathrm{v}_{\mathrm{k}}^{\prime} \mathrm{P} \mathrm{V}_{\mathrm{k}} \\
& \mathrm{V}\left(\mathrm{v}_{\mathrm{k}+1}\right)=1 / 2 \mathrm{~V}_{\mathrm{k}+1}^{\prime} \mathrm{PV}_{\mathrm{k}+1}=1 / 2 \mathrm{v}_{\mathrm{k}}^{\prime}\left(\mathrm{e}^{\mathrm{A}_{\mathrm{c}} \mathrm{T}}\right) \mathrm{Pe}^{\mathrm{A}_{\mathrm{c}} \mathrm{T}} \mathrm{V}_{\mathrm{k}} \\
& \Delta \mathrm{V}_{\mathrm{k}}=-\mathrm{T} / 2 \mathrm{v}_{\mathrm{k}}^{\prime}\left[\mathrm{P}-\left(\mathrm{e}^{\mathrm{A}_{\mathrm{c}} \mathrm{T}}\right) \mathrm{Pe}^{\mathrm{A}_{\mathrm{c}} \mathrm{T}}\right] \mathrm{v}_{\mathrm{k}}<0
\end{aligned}
$$

Is necessary that the term between brackets be positive definite. From this consideration, $\lambda_{\text {min }}(\mathrm{Q})>\lambda_{\text {max }}\left(\left(\mathrm{e}^{\mathrm{A}_{\mathrm{c}} \mathrm{T}}\right)^{\prime} \mathrm{Pe}^{\mathrm{A}_{\mathrm{c}} \mathrm{T}}\right)$.

Could be shown that if we expand the exponential matricial function in linear terms in Theorem 2 we can obtain the result of the Theorem 1, shown that the Theorem 1 is a particular case of the Theorem 2 .

\section{CONCLUSION}

In this work we have presented two possible paths to solve the problem about found analytically the regions of stability in sampled-data control systems. The first path is through the graph norm, disposal only in reference [7] and that presents as a difficult method for obtain the solution of the problem. The second path is more easy to calculate and a general result was presented in theorem 2 . In a next work we will present results using many methods of numerical approximations for the exponential function (like rational forms of Padé, Chebyshev, and others), Lagrange-Sylvester, etc, as extensions of Theorem 2. 


\section{REFERENCES}

[1] Tredinnick, M.R.AC.T.; Souza, M.L.O.; Souza, L.C.G.; Silveira, M.A. Sampling-Period influence in performance and stability in Sampled-Data control systems. SAE Congress, November 2003.

[2] Tredinnick, M.R.AC.T. The Presence of Bifurcation in a Closed-Loop Discrete Control of a Flexible Benchmark Plant analyzed from the Jury Stability Criterion. SAE Congress, November 2001.

[3] Balas, M.J. Discrete-Time Stability of ContinuousTime Controller Designs for Large Space Structures. J. Guidance, Control and Dynamics. v.5, n.5, sept./oct. 1982.

[4] Fadeeva, V.N. Computational Methods of Linear Álgebra. Dover, 1959.

[5] Baker, G.A.; Graves-Morris, P.; Garruthers, P.A. Padé Approximants. Addison-Wesley, 1981.

[6] Burden, R.L.; Faires, J.D. Numerical Analysis. ITP, 1997.

[7] Vidyasagar, M. Constrol System Synthesis: a factorization approach. MIT press, 1985.

[8] Oden, J.T. Applied FunctionalAnalysis. Prentice-Hall, 1979 .

[9] La Salle, J.; Lefschetz, S. Stability by Liapunov's Direct Meted. Academic Press, 1961.

[10] Franklin, G.F.; Powell, D. Digital control of dynamic systems. Reading: Addison-Wesley, 1981.

[11] Katz, P. Digital control using microprocessors. Englewood Cliffs: Prentice-Hall, 1981.

[12] Chen, T.; Francis, B. Optimal Sampled-Data Control Systems..Springer, 1995.

[13] D’Azzo, J.J.; Houpis, C.H. Linear Control System Analysis and Design. McGraw-Hill, 1981.

\section{APPENDIX: $\underline{\text { A BRIEF }}$ TUTORIAL $\underline{\text { ABOUT }}$ THE GRAPH NORM}

In this appendix we will show as to use the graph norm ${ }^{[7]}$ essaying steps for application to the problem in question: analytical detection of the influence of the sampling-period in the stability of sampled-data control systems. Some definitions and preliminary considerations are important,

Definition 1: GRAPH. The graph of a plant $P$ if the set of all pairs input-output bounded. More accurate, if $\mathrm{S}$ is the set of all stable rational-proper and scalar functions and $\mathrm{P} \in \mathrm{R}(\mathrm{s})^{\mathrm{n}+\mathrm{m}}$ then the graph of $\mathrm{O}$ is given by:

$$
\mathrm{G}_{\mathrm{S}}(\mathrm{P})=\underset{\mathrm{S}}{\operatorname{graph}}(\mathrm{P}) \doteq\left\{(\mathrm{u}, \mathrm{y}) \in \mathrm{S}^{\mathrm{n}+\mathrm{m}}: \mathrm{y}=\mathrm{Pu}\right\}
$$

Definition 2:: the set $H_{P}$ is made of all analytical functions $f$ in the open unit disk D that,

$$
\|\mathrm{f}\|_{\mathrm{p}} \doteq \sup _{\mathrm{r} \in(0,1)}\left[\frac{1}{2 \pi} \int_{0}^{2 \pi}\left|\mathrm{f}\left(\mathrm{r} \cdot \mathrm{e}^{\mathrm{j} \theta}\right)\right|^{\mathrm{p}} \mathrm{d} \theta\right]^{1 / 2}<\infty
$$

Definition 3:: the set $\mathrm{H}_{\infty}$ is made of all analytical functions in D that,

$$
\|\mathrm{f}\|_{\infty} \stackrel{\bullet}{=} \sup _{\mathrm{r} \in(0,1)} \max _{\theta \in[0,2 \pi]}\left|\mathrm{f}\left(\mathrm{r} \cdot \mathrm{e}^{\mathrm{j} \theta}\right)\right|<\infty
$$

Definition 4: is possible to define $\|f\|_{\infty}$ when $f(z)$ in $D$ is described as a non-tangencial limit for $\mathrm{r} \rightarrow 1, \mathrm{z} \rightarrow \mathrm{e}^{\mathrm{j} \theta}$, that is described by the essential supremum,

$$
\|\mathrm{f}\|_{\infty} \stackrel{\bullet}{=} \underset{\theta \in[0,2 \pi]}{\operatorname{ess} . \sup }\left|\mathrm{f}\left(\mathrm{e}^{\mathrm{j} \theta}\right)\right|
$$

Exemple: be $\mathrm{P}(\mathrm{s})=\frac{1}{\mathrm{~s}-1}$ na instable plant. A value $\mathrm{u}$ bounded at the input that provokes a bounded output y can be $\mathrm{u}=(\mathrm{s}-1)$,

$$
\begin{aligned}
& P(s)=\frac{y(s)}{u(s)}=\frac{1}{s-1} \\
& \left.y(s)\right|_{u=(s-1)}=1
\end{aligned}
$$

Hence, $(\mathrm{u}, \mathrm{y}) \in \mathrm{S}^{2},\left.(\mathrm{u}, \mathrm{y})\right|_{\mathrm{u}=(\mathrm{s}-1)} \in \operatorname{graph}(\mathrm{P})$.

Assume now that $\mathrm{H}_{\infty}^{+}$is the set of all stable rational-proper funtions analytical at the right half-plane s (that do not have poles in this region). Assume also that $\mathrm{H}_{\infty}^{-}$is the set of all instable functions (not-analytical at the rigth half-plane s). Be $\mathrm{f} \in \mathrm{H}_{\infty}^{+}$. The Infinite-Norm of $\mathrm{f}$ can be described by the discrete case by,

$$
\|\mathrm{f}\|_{\infty} \doteq \sup _{\mathrm{r} \in(0,1)} \max _{\theta \in[0,2 \pi]}\left|\mathrm{f}\left(\mathrm{r} \cdot \mathrm{e}^{\mathrm{j} \theta}\right)\right|<\infty
$$

or to the continuous case,

$$
\|\mathrm{f}\|_{\infty} \doteq \sup _{\omega}|\mathrm{f}(\mathrm{j} \omega)|<\infty
$$




$$
\|f\|_{\infty}=\sup _{\omega} \sqrt{f(s) f(-s)}=\sup _{\omega} \sqrt{f(j \omega) f(-j \omega)}
$$

Example: be $\mathrm{f} \in \mathrm{H}_{\infty}^{+}, \mathrm{f}: \mathrm{C} \rightarrow \mathrm{C}$, calculate $\|\mathrm{f}\|_{\infty}$ when $f(s)=\frac{1}{s+1}$.

$$
\|f(s)\|_{\infty}=\|f(j \omega)\|_{\infty}=\sup _{\omega} \sqrt{f(j \omega) f(-j \omega)}
$$

$$
\begin{aligned}
& \|\mathrm{f}\|_{\infty}=\sup _{\omega} \sqrt{\left(\frac{1}{j \omega+1}\right) \cdot\left(\frac{1}{-j \omega+1}\right)}= \\
& =\sup _{\omega} \sqrt{\frac{1}{\omega^{2}+1}}=\sup _{\omega} \frac{1}{\sqrt{\omega^{2}+1}}=1
\end{aligned}
$$

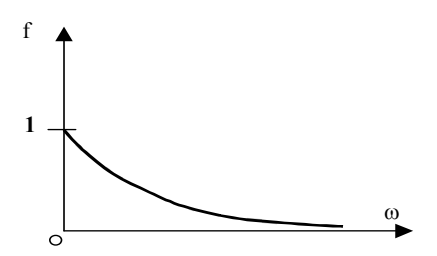

Example: be $\mathrm{f} \in \mathrm{H}_{\infty}^{-}, \mathrm{f}: \mathrm{C} \rightarrow \mathrm{C}$, calculate $\|\mathrm{f}\|_{\infty}$ when $f(s)=\frac{1}{s-1}$.

Similarly,

$$
\|f\|_{\infty}=\sup _{\omega} \sqrt{\left(\frac{1}{j \omega-1}\right) \cdot\left(\frac{1}{-j \omega-1}\right)}=\sup _{\omega} \frac{1}{\sqrt{\omega^{2}+1}}=1
$$

Example: be now $\mathrm{f}: \mathrm{C} \rightarrow \mathrm{C}$, calculate $\|\mathrm{f}\|_{\infty}$ when $\mathrm{f}(\mathrm{s})=\frac{1}{\mathrm{~s}}$.

$$
\|\mathrm{f}\|_{\infty}=\sup _{\omega}\left|\frac{1}{j \omega}\right|=\sqrt{\left(\frac{1}{j \omega}\right) \cdot\left(\frac{1}{-j \omega}\right)}=\sup _{\omega} \frac{1}{\omega}=\infty
$$

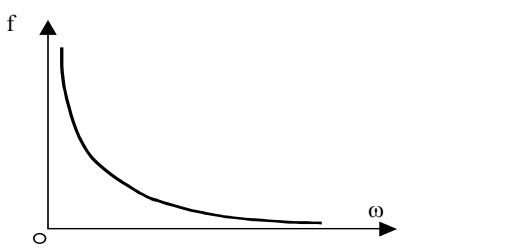

It is clear that the obtained result does not describe a norm $\|\cdot\|$ that must be a continuous positive definite function ${ }^{[7,8]}$. Hence it does not pertains to none metric spaces.

In front this difficulty Vidyasagar ${ }^{[7]}$ hás proposed a new measure named graph metric, as we will see here. Assume that

$$
\mathrm{f}(\mathrm{s})=\frac{\mathrm{n}(\mathrm{s})}{\mathrm{d}(\mathrm{s})}, \quad \mathrm{n}, \mathrm{d} \in \mathrm{H}_{\infty}^{+}
$$

Be, $\mathrm{z} \in \mathrm{H}_{\infty}^{+}, \mathrm{z}^{-1} \in \mathrm{H}_{\infty}^{+}$,

$$
\mathrm{f}(\mathrm{s})=\frac{\mathrm{n}(\mathrm{s}) \cdot \mathrm{z}(\mathrm{s})}{\mathrm{d}(\mathrm{s}) \cdot \mathrm{z}(\mathrm{s})}, \quad \mathrm{n} \cdot \mathrm{z}, \mathrm{d} \cdot \mathrm{z} \in \mathrm{H}_{\infty}^{+}
$$

The graph metric of $\mathrm{f}=\mathrm{P}$ when $\mathrm{P}$ is the plant used is given by:

$$
\delta(\mathrm{P}, 0)=\inf _{\mathrm{z} \in \mathrm{S}}\|\mathrm{d} \cdot \mathrm{z}, \mathrm{n} \cdot \mathrm{z}\|_{\infty}
$$

Where $\mathrm{S}$ is the set of the stable rational-proper and scalar funtions. If the graph of $\mathrm{P}$ is a set defined by,

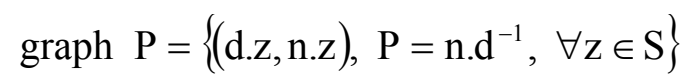

Finally the graph norm will be defined by,

$$
\|(\mathrm{d} . \mathrm{z}, \mathrm{n} . \mathrm{z})\|_{\infty} \dot{\dot{ }}=\inf \left\{\|\mathrm{d} . \mathrm{z}\|_{\infty},\|\mathrm{n} . \mathrm{z}\|_{\infty}\right\}=\|\mathrm{P}\|_{\text {Grafo }}
$$

To obtain quantitative results we must metrizing the graph topology, i.e., we must define a metric over $\mathrm{M}(\mathrm{R}(\mathrm{s}))$ that the convergence (and consequently the continuity) be equivalent to the convergence in the graph topology. This is the graph metric. Before we will define some concepts.

Definition: normalized r.c.f. A r.c.f. ("right coprime factorization") of $\mathrm{P} \in \mathrm{M}(\mathrm{R}(\mathrm{s}))$ is said to be normalized if $\mathrm{N}^{*}(\mathrm{~s}) \mathrm{N}(\mathrm{s})+\mathrm{D}^{*}(\mathrm{~s}) \mathrm{D}(\mathrm{s})=\mathrm{I} \quad \forall \mathrm{s} \quad$ nde
$\mathrm{N}^{*}(\mathrm{~s})=\mathrm{N}^{\prime}(-\mathrm{s})$. 
Definition: GRAPH METRIC. Suppose $\mathrm{P}_{1}, \mathrm{P}_{2} \in \mathrm{M}(\mathrm{R}(\mathrm{s}))$ with the same dimension and $\left(\mathrm{N}_{\mathrm{i}}, \mathrm{D}_{\mathrm{i}}\right)$ a normalized r.c.f. of $\mathrm{P}_{\mathrm{i}}$ for $\mathrm{i}=1,2$. Therefore:

$A_{i}=\left[\begin{array}{c}D_{i} \\ N_{i}\end{array}\right], i=1,2$.

And define,

$\delta\left(\mathrm{P}_{1}, \mathrm{P}_{2}\right)=\inf _{\mathrm{U} \in \mathrm{M}(\mathrm{S}),\|\mathrm{U}\| \leq 1}\left\|\mathrm{~A}_{1}-\mathrm{A}_{2} \mathrm{U}\right\|$

Where $\mathrm{U}$ is the spectral factor of the identity matrix $\mathrm{I}=\mathrm{U}^{\prime} . \mathrm{U}$.

$\mathrm{d}\left(\mathrm{P}_{1}, \mathrm{P}_{2}\right)=\max \left\{\delta\left(\mathrm{P}_{1}, \mathrm{P}_{2}\right), \delta\left(\mathrm{P}_{2}, \mathrm{P}_{1}\right)\right\}$.

Then $\mathrm{d}\left(\mathrm{P}_{1}, \mathrm{P}_{2}\right)$ is the graph metric in $\mathrm{M}(\mathrm{R}(\mathrm{s}))$.

Lema: $d$ is a metric in $M(R(s))$ assuming values in the interval $[0,1]$.

Theorem: this is the main result about convergency of the graph metric. A sequence $\left\{\mathrm{P}_{\mathrm{i}}\right\}$ in $\mathrm{M}(\mathrm{R}(\mathrm{s}))$ converges to $\mathrm{P} \in \mathrm{M}(\mathrm{R}(\mathrm{s}))$ in the graph topology if only if $\mathrm{d}\left(\mathrm{P}_{\mathrm{i}}, \mathrm{P}\right) \rightarrow 0$.

Until here the graph metric does not could be calculate exactly due the problem to calculate the infimun is na opening study (see [7] for details). Therefore is possible calculate lower and upper bounds to contour thi problem.

Lema: Suppose $\left(\mathrm{N}_{1}, \mathrm{D}_{1}\right)$ a normalized r.c.f. of $\mathrm{P}_{1}$ and $\left(\mathrm{N}_{2}, \mathrm{D}_{2}\right)$ a r.c.f. (not necessarily normalized) of $\mathrm{P}_{2}$ and $A_{1}=\left[\begin{array}{ll}D_{1}^{\prime} & N_{1}^{\prime}\end{array}\right]$ e $M_{2}=\left[\begin{array}{ll}D_{2}^{\prime} & N_{2}^{\prime}\end{array}\right]$. Suppose now that,

$\left\|\mathrm{A}_{1}-\mathrm{M}_{2}\right\| \doteq \gamma<1$

then,

$\mathrm{d}\left(\mathrm{P}_{\mathrm{i}}, \mathrm{P}\right) \leq \frac{2 \gamma}{1-\gamma}$.

To calculate a lower bound of the metric distance of the graph between two plants (uma referência $\left.P_{o}\right|_{T=0}$ e outra $P_{1}$ para um $\mathrm{T}>0$, por exemplo) we must note that,

$\delta\left(\mathrm{P}_{0}, \mathrm{P}_{1}\right)=\inf _{\mathrm{R} \in \mathrm{M}(\mathrm{S})}\left\|\mathrm{A}_{0}-\mathrm{A}_{1} \mathrm{R}\right\|$

where $A_{i}=\left[\begin{array}{l}D_{i} \\ N_{i}\end{array}\right]$,

and calculate,
$\mathrm{d}\left(\mathrm{P}_{0}, \mathrm{P}_{1}\right)=\max \left\{\delta\left(\mathrm{P}_{0}, \mathrm{P}_{1}\right), \delta\left(\mathrm{P}_{1}, \mathrm{P}_{0}\right)\right\}$

Example: if $\mathrm{f}: \mathrm{C} \rightarrow \mathrm{C}$, calculate $\|\mathrm{f}\|_{\text {Grafo }}$ para $\mathrm{f}(\mathrm{s})=\frac{1}{\mathrm{~s}}$.

Assume, for example, $\mathrm{z}=\frac{\mathrm{s}+2}{\mathrm{~s}+3}$.

$\mathrm{f}(\mathrm{s})=\frac{1 \cdot \frac{1}{\mathrm{~s}+1}}{\mathrm{~s} \cdot \frac{1}{\mathrm{~s}+1}}=\frac{\frac{1}{\mathrm{~s}+1}}{\frac{\mathrm{s}}{\mathrm{s}+1}}=\frac{\mathrm{n}}{\mathrm{d}}, \quad \mathrm{n}, \mathrm{d} \in \mathrm{H}_{\infty}^{+}$

$f(s)=\frac{N \cdot z}{D \cdot z}=\frac{\frac{1}{s+1} \cdot \frac{s+2}{s+3}}{\frac{s}{s+1} \cdot \frac{s+2}{s+3}}, \quad n z, d z \in H_{\infty}^{+}$

$\|(\mathrm{d} . \mathrm{z}, \mathrm{n} . \mathrm{z})\|_{\infty} \doteq \inf \left\{\|\mathrm{d} . \mathrm{z}\|_{\infty},\|\mathrm{n} . \mathrm{z}\|_{\infty}\right\}$

Example: if $\mathrm{f}: \mathrm{C} \rightarrow \mathrm{C}, \quad$ calculate $\|\mathrm{f}\|_{\text {Grafo }}$ for $f(s)=\frac{1}{s .(s+1)}$.

$\mathrm{A}_{1}=0$

$\mathrm{A}_{2}=\frac{1}{\mathrm{~s}(\mathrm{~s}+1)}=\frac{\frac{1}{(\mathrm{~s}+1)^{2}}}{\frac{\mathrm{s}}{(\mathrm{s}+1)}}$

$\delta\left(0, \frac{1}{s(s+1)}\right)=\inf _{\| \mathrm{U} \leq 1} \|\left(\begin{array}{c}\frac{1}{(\mathrm{~s}+1)^{2}} \\ \frac{\mathrm{s}}{(\mathrm{s}+1)}\end{array}\right) \cdot \mathrm{U}$

$\delta\left(0, \frac{1}{\mathrm{~s}(\mathrm{~s}+1)}\right)=\max \left\{\left\|\frac{1}{(\mathrm{~s}+1)^{2}}\right\|_{\infty},\left\|\frac{\mathrm{s}}{(\mathrm{s}+1)}\right\|_{\infty}\right\}$

Doing s=-s: $\frac{-j \omega}{-j \omega+1}=\frac{\omega^{2}-j \omega}{1+\omega^{2}}$, with modulus: $\frac{\sqrt{\omega^{4}+\omega^{2}}}{1+\omega^{2}}$,

$\delta\left(0, \frac{1}{\mathrm{~s}(\mathrm{~s}+1)}\right)=\max \left\{\left\|\frac{1}{(\mathrm{~s}+1)^{2}}\right\|_{\infty},\left\|\frac{\mathrm{s}}{(\mathrm{s}+1)}\right\|_{\infty}\right\}=1$

Finaly, the distance of the function $\mathrm{f}(\mathrm{s})=\frac{1}{\mathrm{~s} .(\mathrm{s}+1)}$ to the origin is equal to 1 . 